\title{
POST-TRAUMATIC AVASCULAR NECROSIS OF THE FEMORAL HEAD IN CHILDREN
}

\author{
Report of Two Cases \\ Jörgen Stougård, Copenhagen, Denmark \\ From the Department II of Orthopaedics in Copenhagen
}

Post-traumatic necrosis of the femoral head in children is rare. It is most often seen after a fracture of the neck or dislocation of the hip. According to Ratliff (1962) the fractures causing necrosis follow violent trauma and are often displaced transcervical or basal fractures. He found thirty children with necrosis out of seventy suffering fracture, an incidence of 42 per cent. Pertrochanteric, non-displaced fractures or fissures can, however, cause necrosis of the head (Durbin 1959, Ratliff 1962). Dislocation of the femoral head in children was recently discussed in an article from the Pennsylvania Orthopaedic Society (1968): together with the cases published earlier in the literature there was a total number of 266 hips, of which twenty-six (10 per cent) showed necrosis of the femoral head. The conclusion was that the violence of the injury together with either fracture of the neck or delayed reduction of a dislocation were among the most important factors in the development of necrosis. The basic cause of necrosis is supposed to be damage to the vessels passing along the neck of the femur at an age when the anastomoses through the ligament of the head are not yet developed (Trueta and Harrison 1953).

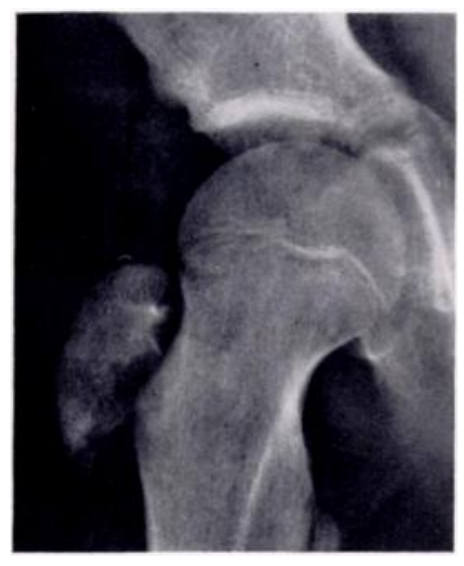

FIG. 1

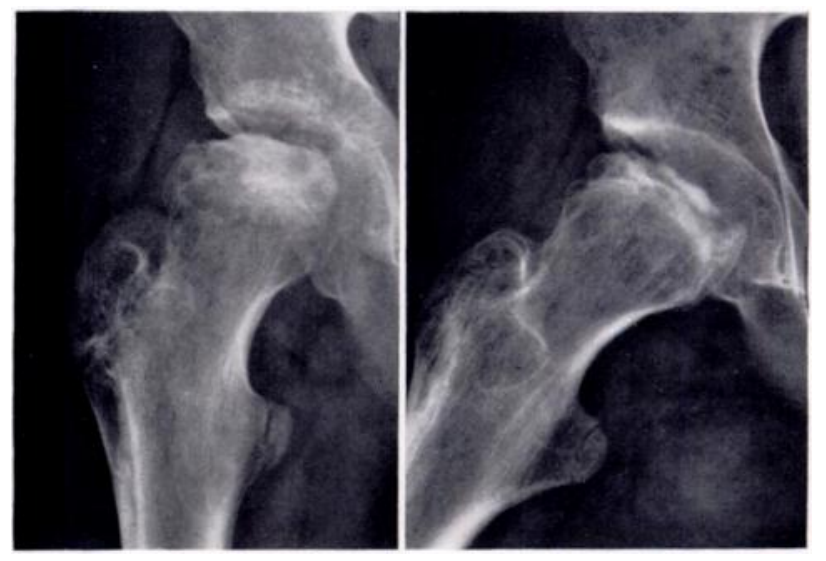

FIG. 2

Case 1. Figure 1-Initial radiograph showing an avulsion fracture of the greater trochanter. Figure 2-Five months after injury, showing avascular necrosis of the head. The greater trochanter has united in normal position.

\section{CASE REPORTS}

Case 1-A boy aged thirteen years, previously healthy, fell from a tractor and struck his right hip. He complained of pain in the hip and could not stand on the right leg. The first radiograph showed avulsion of the greater trochanter without fracture of the head or neck or dislocation of the head (Fig. 1). The boy was treated with bed rest and active exercises for six weeks, after which weight-bearing was allowed. Five months after the accident the boy again complained of pain in the hip and began to limp. The radiograph now showed healing of the greater trochanter in good position, but there was evidence of aseptic necrosis 
of the head, with flattening of the supero-lateral part and sclerosed bone underneath (Fig. 2). Treatment was by rest in bed with balanced traction on the leg for six months. The boy is now walking with a caliper, but there are still gross changes in the head.

Case 2-A boy aged eleven years, previously healthy, fell from a hayload and sustained head injuries and damage to the left shin as well as a direct injury to the right hip. He complained at once of pain in the hip. The first radiograph showed nothing other than slight increase of the joint space (Fig. 3). Treatment was by rest in bed. Flexion and abduction contracture developed in the right hip and rotation was restricted. Six weeks after the accident the radiograph still showed increased joint space, and now there was also flattening and relative sclerosis of the femoral head in contrast to the osteoporosis of the acetabulum, neck and

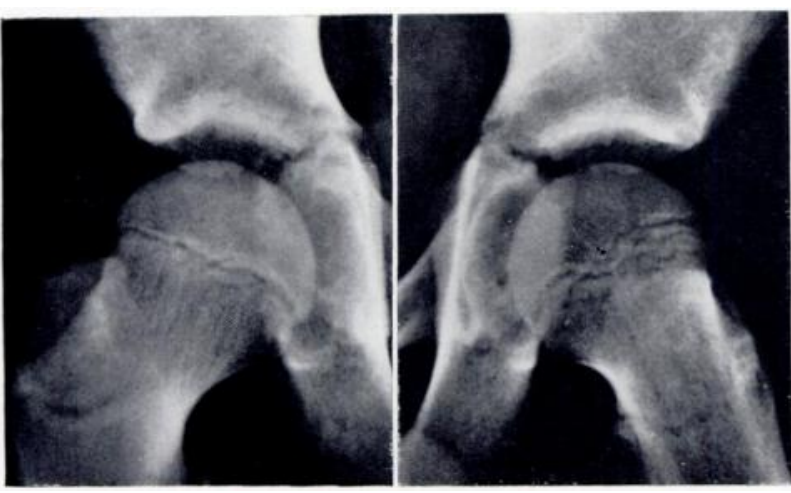

FIG. 3

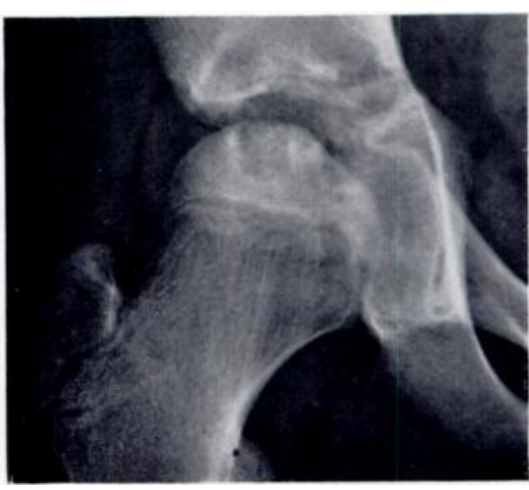

FIG. 4

Case 2. Figure 3-Initial radiographs showing only a slight increase of the joint space of the right hip. Figure 4A year later there are cystic changes and irregularity of the supero-lateral part of the head and relative sclerosis underneath, as in partial avascular necrosis.

trochanteric region. Treatment by bed rest and traction was continued. The contracture has now disappeared and the boy is walking with a caliper. The radiograph a year after the injury shows the same changes as before, plus cystic changes and small irregularities of the articular surface of the head (Fig. 4). Both boys had normal sedimentation rate and there was no sign of infection.

\section{DISCUSSION}

In these two cases there was post-traumatic avascular necrosis of the head of the femur without dislocation of the head or fracture of the head or neck. It is just possible that momentary dislocation had been present and had been spontaneously reduced before admission to the hospital. Another possibility is that there was a fracture not seen on the radiograph. The haematoma and the oedema in the region may possibly act on the blood vessels, for example by venous compression.

\section{SUMMARY}

Two cases of post-traumatic avascular necrosis of the head of the femur without evident dislocation of the head or fracture of the head or neck are recorded.

\section{REFERENCES}

Durbin, F. C. (1959): Avascular Necrosis Complicating Undisplaced Fractures of the Neck of Femur in Children. Journal of Bone and Joint Surgery, 41-B, 758.

Ratuiff, A. H. C. (1962): Fractures of the Neck of the Femur in Children. Journal of Bone and Joint Surgery, 44-B, 528.

The Scientific Research Committee of the Pennsylvania Orthopaedic Society (1968): Traumatic Dislocation of the Hip Joint in Children. Final Report. Journal of Bone and Joint Surgery, 50-A, 79.

Trueta, J., and Harrison, M. H. M. (1953): The Normal Vascular Anatomy of the Femoral Head in Adult Man. Journal of Bone and Joint Surgery, 35-B, 442.

VOL. 51 B, NO. 2, MAY 1969 